\title{
Core and double bond functionalization of Cyclopentadithiophene- phosphaalkenes
}

Jordann A.L. Wells, ${ }^{a, \#}$ M uhammad Anwar Shameem, ${ }^{\text {a,\# }}$ Arvind Kumar Gupta, ${ }^{\text {a }}$ Andreas Orthaber*,a

aSymthetic M olecular Chemistry. Department of Chemistry - Ångström laboratories.

Uppsala University. Box 523, 75120 Uppsala Sweden.

\#These authors contributed equally to this work

* correspondence should be addressed to A.0.: andreas.orthaber@kemi.uu.se

\begin{abstract}
Abtract
The heterofulvenoid cyclopentadithiophene-phosphaalkene is a versatilie building block for opto-electronic tuning with donor and acceptor moieties. Both the annulated thienyl rings and the phosphaalkene bond can be functionalised using a variety of chemical transfomations, e.g. forming C-C, C-E (E =Si, Br) bonds or oxidation and metal coordination, respectively. Solid-state structures, optical and electronic properties are probed theoretically and experimentally, illustrating the opto-electronic tailoring opportunities at this motif.
\end{abstract}

\section{Introduction}

Combining electron donor and electron acceptor units to tailor the HOMO and LUMO of dye molecules has been an extensively used concept in the design of dyes for sensors, solar cells, etc. ${ }^{1}$ In the cyclopentadithiophene (CPDT) motif two thiophene units are linked using a methylene bridge improving the orbital delocalization by removing a torsional degree of freedom, i.e. planarizing the conjugated system. ${ }^{2} \mathrm{M}$ oreover, functionalization at the bridgehead positions allowed addressing of the solubility (Figure 1, I) and electronic nature of this annulated bithiophene framework. ${ }^{2-3}$ In particular, electron deficient bridgehead substituents, e.g. ketone (II) and dicyanoalkenes (III) have led to interesting opto-electronic materials and building blocks for donor-acceptor polymers, in which the exocyclic fulvenoid repeating unit acts as an outstanding acceptor unit. ${ }^{4}$ Recently, examples of imine functionalized CPDT units have been incorporated into polymers allowing controlled modifications of the HOMO and LUMO levels of the molecular components. ${ }^{5}$ The diagonal relationship of phosphorus and carbon has led to a variety of conjugated compounds in which carbene fragments of double bonds are replaced by isolobal phosphinidenes giving rise to phosphaalkenes. ${ }^{6}$ The introduction of this group 15 heteroelement as part of conjugated frameworks has noticeable stabilizing effects on the LUMO levels, while the HOMO remains almost unaltered. In these building blocks, the low-lying heteroalkene $\pi^{*}$ orbitals provide an acceptor group resulting in applications as opto-electronic materials. ${ }^{7}$ The marked difference to its lighter homologue, i.e. the imine derivatives, hold promising developments for the heavier pnictaalkene systems. Interesting approaches have been already pursued to translate the molecular phosphaalkene motifs into polymeric materials, ${ }^{8}$ both by keeping the $\mathrm{P}=\mathrm{C}$ motif intact and using it as polymerizable unit. ${ }^{9}$ Furthermore, the lone pair at the phosphaalkene can easily be functionalized by metal coordination allowing for catalytic applications, ${ }^{10}$ but also altering the opto-electronic properties. ${ }^{11} \mathrm{~A}$ significantly lesser explored but equally powerful $\mathrm{P}=\mathrm{C}$ functionalisation is its oxidation with chalcogens ${ }^{12}$ and coordination by $\mathrm{NHCs} .{ }^{13}$ 
<smiles>[R]C1([R])c2ccsc2-c2sccc21</smiles>

(I) $R=a \mid k y l$<smiles>O=C1c2ccsc2-c2sccc21</smiles>

(II)<smiles>N#CC(C#N)=C1c2ccsc2-c2sccc21</smiles>

(III)

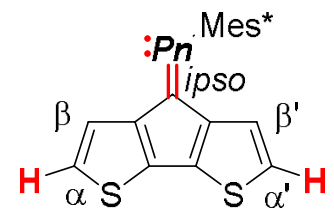

$A(P n=P)$
This work<smiles></smiles>

B $(P n=A s)$

Figure 1. Literature known CPDT-derivatives (I - III), phospha/arsaalkene-CPDT-derivative $\mathbf{A}$ and $\mathbf{B}$, and novel derivatives studied in this work.

In view of these properties, we have already described the synthesis and excited state behaviour of phospha- and arsaalkene functionalized cyclopentadithiophene derivatives, where the heteroalkenes lead to pronounced acceptor character by stabilizing the heterofulvenoid-type antibonding orbitals. The elemental substitution (phosphorus vs. arsenic) and metal coordination ( $\mathrm{AuCl}$ ) allowed us to address the energy and dynamics of the lowest energy transitions. ${ }^{14}$

In this manuscript, we address the further functionalization of the CPDT-phosphaalkene core by metal coordination or oxidation at the heteroalkene and chemical functionalization at the thiophene rings. The impact of these functionalizations is illustrated by comparing electronic spectra and electro-chemistry data.

\section{Results and Discussion}

Cyclopentadithiophene phosphaalkene $\mathbf{A}$ is synthesized according to published procedures from readily available starting materials. ${ }^{14}$ In order to study the versatility of this building block we initially investigated the derivatization of the thiophene rings using standard organic functionalizations.
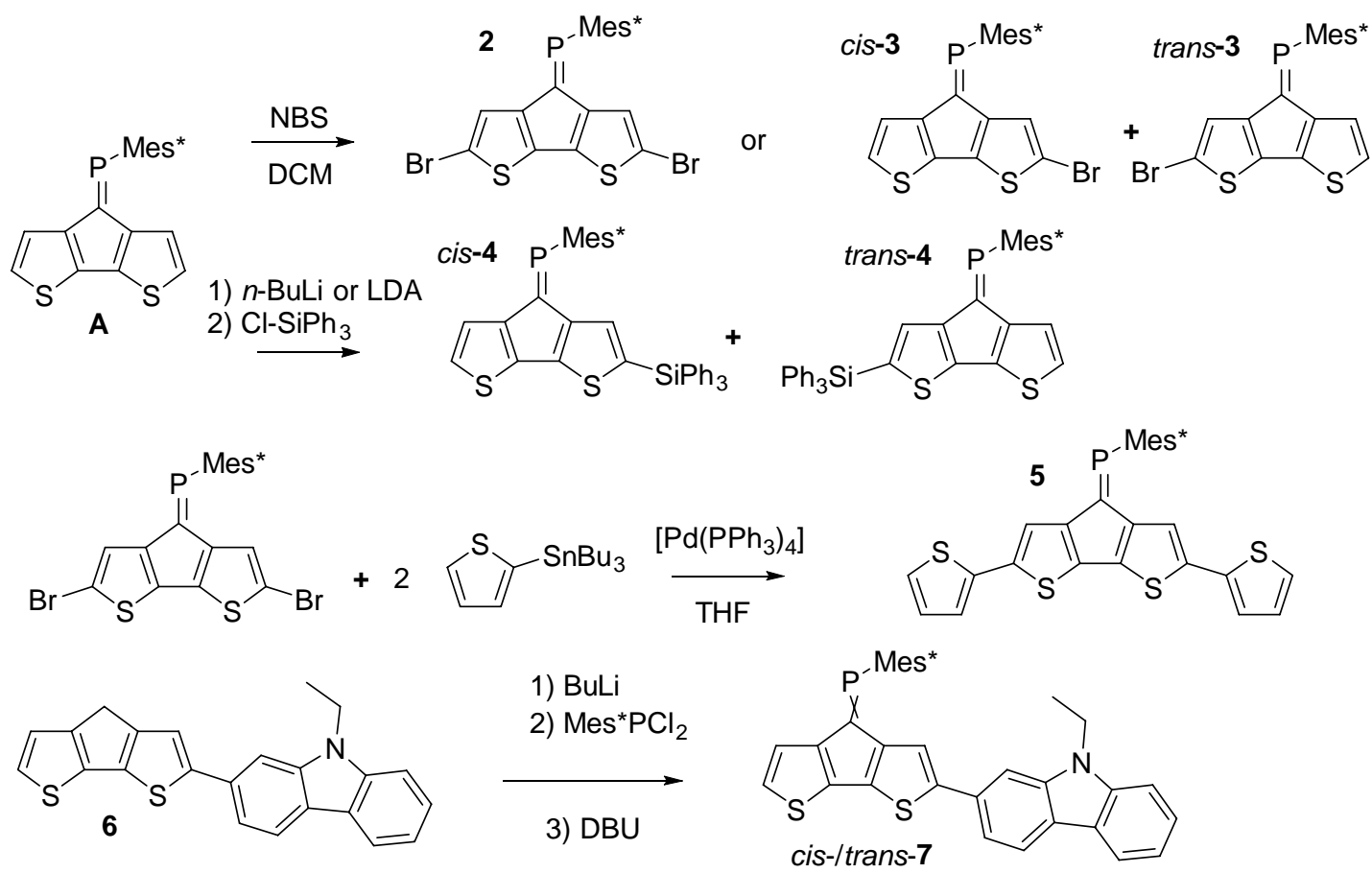

Scheme 1. Functionalisations of parent CPDT phosphaalkene $\mathbf{A}$ giving brominated (3), silylated (4), dithienyl (5) and carbazole (7) derivatives. Further experimental details are summarized in the experimental section and the supporting information. 
Expectedly, the bromination with N-bromo succinimide (NBS) occurs selectively at the $\alpha, \alpha^{\prime}$-positions under ambient conditions and ultrasonication. Chromatographic workup afforded the dibrominated derivative $\mathbf{2}$ in approx. 75\% isolated yields. Attempts to synthesize the corresponding mono-brominated derivatives cis-3 and trans-3 using strictly one equivalent of NBS and low reaction temperatures suffer from unselective reactivities, affording a statistical mixture of $\mathbf{A}, \mathbf{2}$ and both isomers of $\mathbf{3}$. The two mono-brominated isomers can be separated chromatographically, however isomerization within a couple of hours establishes the mixture of cis/trans-3 isomers. The conditions which trigger phosphaalkene $\mathrm{E}-/ \mathrm{Z}$ isomerisation (e.g. light etc) seem highly dependent on the steric and electronic nature of the substituent and are less explored and understood ${ }^{15}$ compared to the diphosphene E-Z isomerisation. ${ }^{16}$

The electron withdrawing effect of the bromide substituent on the remote $\mathrm{P}=\mathrm{C}$ bond is clearly visible in the 31P NM R spectra, which show resonances shifter to higher frequencies. ( $\delta^{31} \mathrm{P}$ for 2: $269.6 \mathrm{ppm}$; cis-3: $262.9 \mathrm{ppm}$; trans3: $263.1 \mathrm{ppm})$. Compared to $\mathbf{A}$, which has a resonance at $256.6 \mathrm{ppm}$, the addition of each $\mathrm{Br}$-atom shields the resonance by approx. $6 \mathrm{ppm}$. The assignment of the two isomers is based on the coupling constants of the shielded $\beta^{\prime}$ protons positioned below the Mes*-ring current; for cis-3 this characteristic proton ( $\left.4.36 \mathrm{ppm}\right)$ shows as a doublet with a small ${ }^{4} \mathrm{PH}_{\mathrm{PH}}$ coupling of $1.7 \mathrm{~Hz}$. In contrast, trans-3 shows a doublet of doublets (dd) splitting pattern with $\mathrm{a}^{3} \mathrm{JHH}_{\mathrm{H}}=5.1 \mathrm{~Hz}$ and $\mathrm{a}^{4} \mathrm{JPH}_{\mathrm{PH}}=1.5 \mathrm{~Hz}(4.44 \mathrm{ppm})$ coupling constants to the neighboring hydrogen and phosphorous atoms, respectively. Single crystals obtained from slow solvent evaporation of pentane/DCM solutions allowed us to perform single crystal $X$-ray diffraction experiments. The solid-state structure of $\mathbf{2}$ gives a $\mathrm{P}=\mathrm{C}$ bond length of $1.687(2) \AA$, which is slightly longer than that of $\mathbf{A}$, while the $C-P=C$ angle of $102.5(1)^{\circ}$ is almost identical. These metrics suggest that the electronic variation has a larger influence on the bond length than the "hybridization" and steric hindrance, which is more reflected in the angles around the P-center. The packing is dominated by weak slipped $\pi \pi$ interactions (C-centroid distance 3.711(5) $\AA$ ) and $\pi \cdots B$ Br interactions (3.782(1) $\AA$ ).

We further studied the possibility to deprotonate the acidic $\alpha$-positions using a Li-base and reacting the in situformed anion with an electrophile. Compound $\mathbf{A}$ was thus reacted with two equivalents of LDA in THF at low temperatures and then allowed to reach r.t., followed by the addition of triphenyl chlorosilane as an electron accepting substituent. Surprisingly, two new resonances in the ${ }^{31}$ P-NM R spectra are observed indicating formation of two major products. Despite being separable by column chromatography, slow isomerization in solution precluded detailed studies of the isomers. Selective crystallization from the mixture afforded single crystals suitable for X-ray diffraction analysis. Indeed, the solid-state structure of one monosilylated product was confirmed as cis4. This isomer (cis-4) crystallizes in the monoclinic space group $P 2_{1} / C$ (No. 14). The P1-C1 double bond is 1.678(2) $\AA$, slightly longer than in the parent system $(\mathbf{A}: 1.667(5) \AA)$. Despite the cis-orientation of the sterically demanding triphenylsilyl substituent, the C10-P1-C1 angle increases only marginally from $102.6(2)^{\circ}$ in $\mathbf{A}$ to $103.1(1)^{\circ}$ for cis-4. The Si-C9 bond is significantly shorter $(1.852(2) \AA)$ compared to the Si- $C_{\text {phenyl }}$ bonds $(1.862(2)$ to $1.872(2) \AA)$ indicative of negative hyper-conjugation of the CPDT-core with the silyl substituent. The second product is suspected to be the corresponding trans-4, based on proton NMR data, indicating that despite the use of two equivalents of LDA or n-BuLi the double-deprotonation was unsuccessful. 

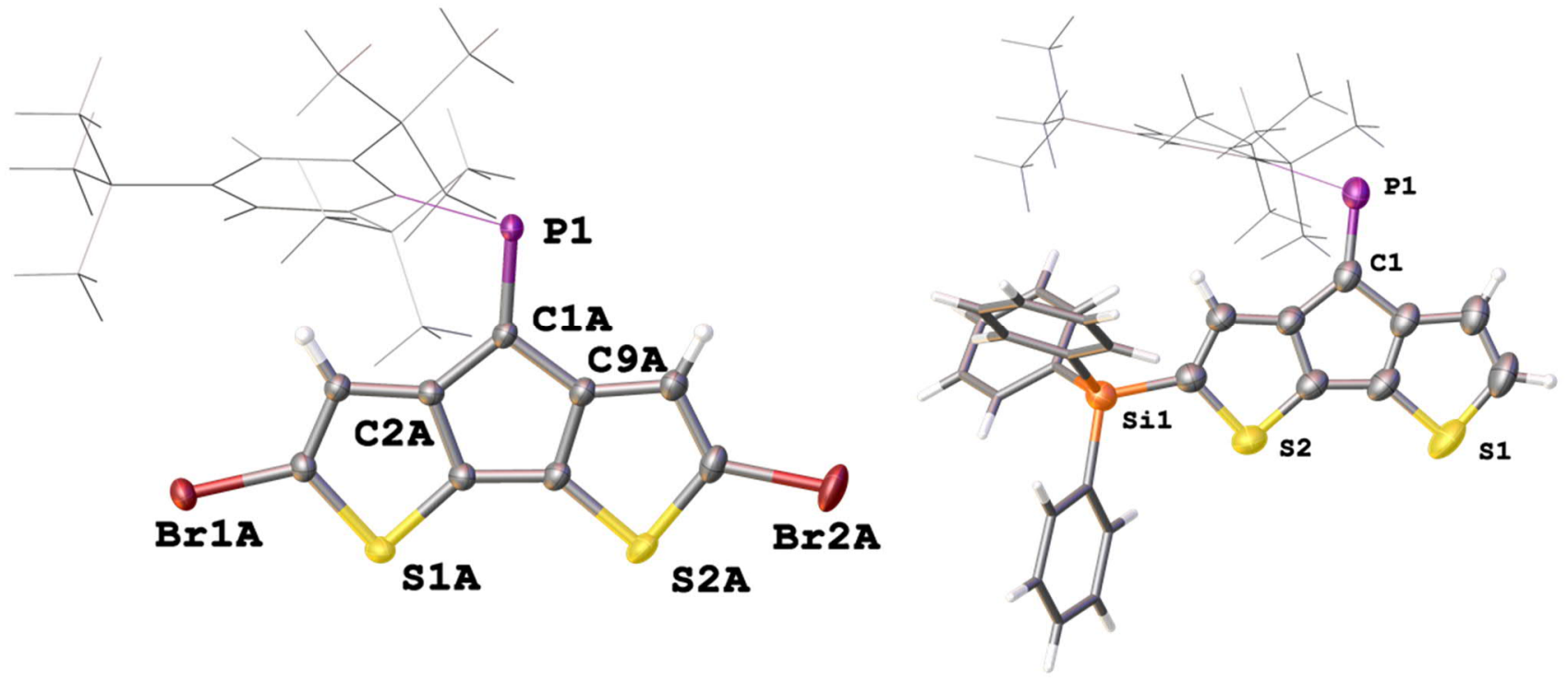

Figure 2. ORTEP plot of the solid-state structure of $\mathbf{2}^{\mathrm{a}}$ and cis-4. Selected atoms are drawn at $50 \%$ probability levels of thermal ellipsoids, while the Mes* and phenyl groups are depicted in the stick model. Selected bond lengths $[\AA]$ and angles [ ${ }^{\circ}$ ]: 2: P1-C1A 1.687(2), P1-C10A 1.841(2), C1A-P1-C10A 102.54(11). cis-4: P1-C1 1.678(2), Si1-C9 1.852(2), Si1-Cipso 1.862(2), 1.867(2). 1872(2), C1-P1-C10(M es*) 103.1(1). ${ }^{a}$ compound 2 shows a positional disorder (0.92:0.08); distances are given for the molecule with the higher occupancy.

The usefulness of 2 as a synthon towards extended conjugated systems was probed using a Stille coupling protocol with 2-tributylstannyl thiophene. The reaction proceeds in moderate yield to give the desired disubstituted product 5 with a ${ }^{31}$ P-NM R resonance of 265.5 ppm, which is quite similar to those of the brominated derivatives.

Further attempts to use the brominated derivatives $\mathbf{2}$ and $\mathbf{3}$ as starting materials in Suzuki type coupling C-C coupling reactions to give extended conjugated systems has proven difficult. In contrast, the carbazole functionalized ketone $\mathbf{5}$ can be prepared from readily available iodinated precursors and undergoes facile WolfKishner reduction to the methylene derivative $\mathbf{6}$. In analogy to the synthesis of $\mathbf{A}$, a two-step, one-pot reaction afforded the desired phosphaalkene as an inseparable isomeric mixture of cis-/ trans-7 in an approximately 1:1 ratio. The two isomers crystallized as slightly differently shaped dark purple blocks. Compound trans-7 crystallizes in the triclinic space group P-1 (No. 2) as a hexane solvate. The disordered solvent molecule is treated by diffuse contribution to the overall scattering using the solvent masking implemented in OLEX2. ${ }^{17}$ Notably, the $P=C$ double bond in trans-7 is even longer $(1.684(2) \AA)$ compared to that of cis-4, while the $\mathrm{C}-\mathrm{P}=\mathrm{C}$ angle $\left(102.6(1)^{\circ}\right)$ is more similar to that found in $\mathbf{A}$. The cis-isomer crystallizes in the monoclinic space group $\mathrm{C} 2 / \mathrm{C}$ (No. 15) as a hexane solvate (removed also by solvent masking). The $P=C$ bond lengths in both isomers are comparable ( $P=C$ : 1.683(3) $\AA$ ), but the $\mathrm{C}-\mathrm{P}=\mathrm{C}$ angle is wider for cis-7 $\left(103.4(1)^{\circ}\right)$ reflecting the steric demand of the substituent on the Mes* position. The most pronounced effect in the different isomers is observed for the orientation of the carbazole moiety and its torsion with respect to the CPDT core. The smaller torsion angle between the two chromophores' planes in trans$7\left(8.74^{\circ}\right)$ gives rise to efficient delocalization, while steric interaction of the large M es* with the carbazole unit leads in cis-7 to an increased torsion angle $\left(21.61^{\circ}\right)$, with the $\mathrm{N}$-ethyl group pointing in the same and opposite direction of the $P=C$ bond, respectively. 


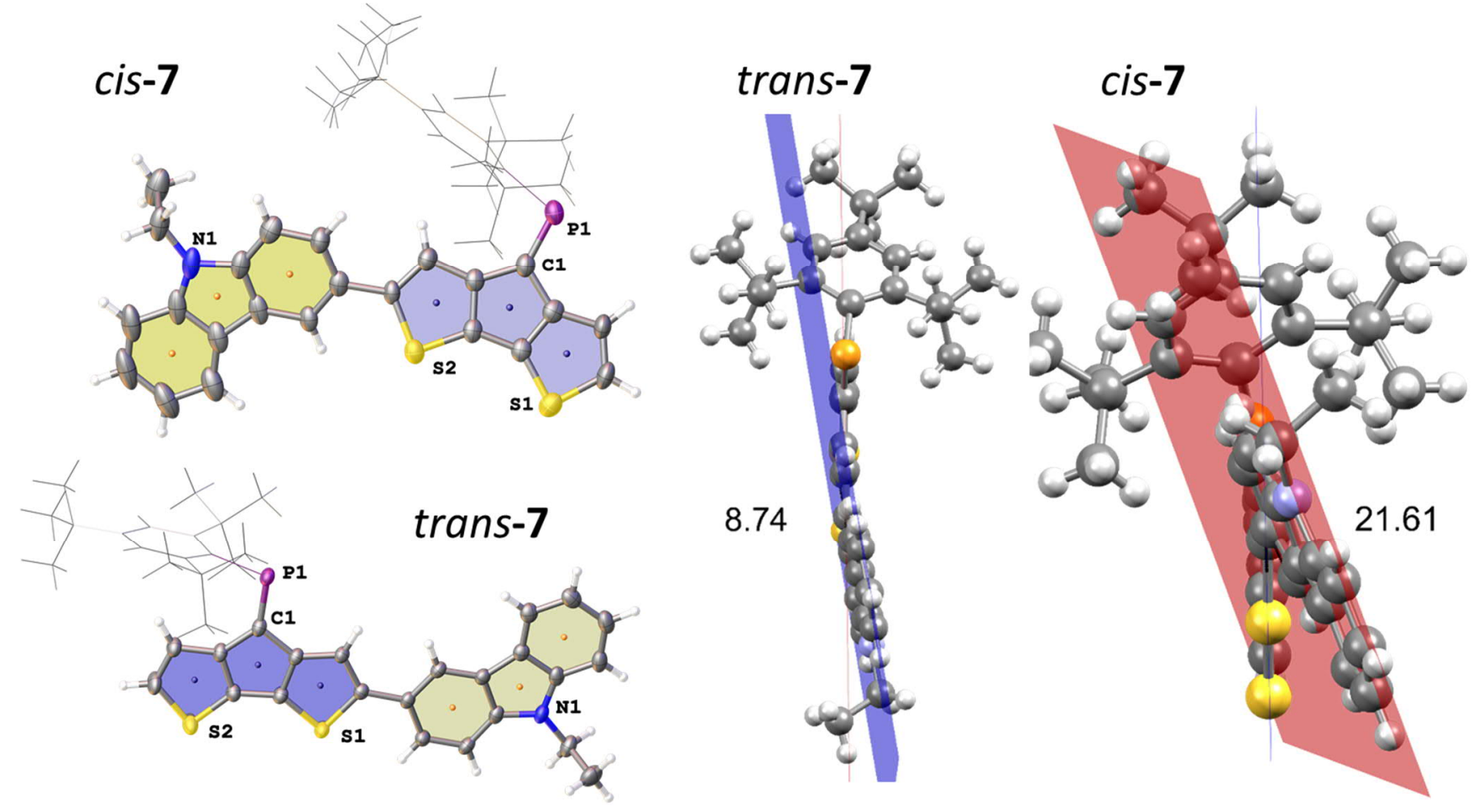

Figure 3. Solid-state structures of cis- and trans-7. Planes through the CPDT and carbazole rings and the torsion angles between both planes (right). Selected bond lengths $[\AA]$ and angles $\left[{ }^{\circ}\right]$ cis-7: P1-C1 1.683(4), P1-C24 1.835(4), C9-C10 1.478(5) C1-P1-C24 103.38(16). trans-7: P1-C1 1.683(3), P1-C24 1.845(2), C9-10 1.467(3), C1-P1-C24 102.59(11).

The previously reported gold(I) complex $[\mathrm{AuCl} * \mathbf{A}]$ is only moderately stable under ambient conditions and slowly decomposes in the presence of water. We report the solid-state structure of $[\mathrm{AuCl} * \mathbf{A}]$ together with one of the decomposition products using single crystal $X$-ray analysis. Complex [AuCl*A] shows fairly short $P=C$ and $P$-Au bonds lengths of $1.668(7)$ and $2.213(2) \AA$, respectively. On the other hand, the C10-P1-C1 angle is fairly large indicating an increase of s-character of the coordinating lone pair. Notably, the almost linear P-AuCl fragment $\left(178.16(8)^{\circ}\right)$ is strongly twisted out of the CPDT plane (angle between the CPDT I.s.pl. and the CI-P vector of $24.15(3)^{\circ}$ ). The solidstate structure of decomposition product 8 reveals the formation of a quasi-dimer of the two tautomeric forms, i.e. the hydroxyphosphine as the hydrogen bond donor and the phosphine oxide as the hydrogen bond acceptor. The trivalent phosphine tautomer is stabilized by one remaining gold(I) chloride fragment still being coordinated, while the phosphine oxide has lost its metal fragment. The colorless crystals solved in the space group P-1 (No. 2). The gold coordination is barely affected by the hydrolysis with typical P-Au and Au-Cl distances of 2.232(1) and $2.298(1) \AA$, respectively. The phosphorus oxygen distances are in the typical range of P-0 single (1.578(3) $\AA$ ) and $\mathrm{P}=0$ double bonds (1.489(3) $\AA$ ). The donor $\cdots$ acceptor distance is $2.550(4) \AA$ and the $\mathrm{O}-\mathrm{H} \cdots \mathrm{O}$ angle $164^{\circ}$ indicating strong hydrogen bonding. ${ }^{18}$ These findings are in line with previous observations of changing the tautomeric forms upon coordination ${ }^{19}$ or shifting the equilibrium towards the hydroxyphopshine tautomer using electron deficient P-substituents. ${ }^{20}$ 

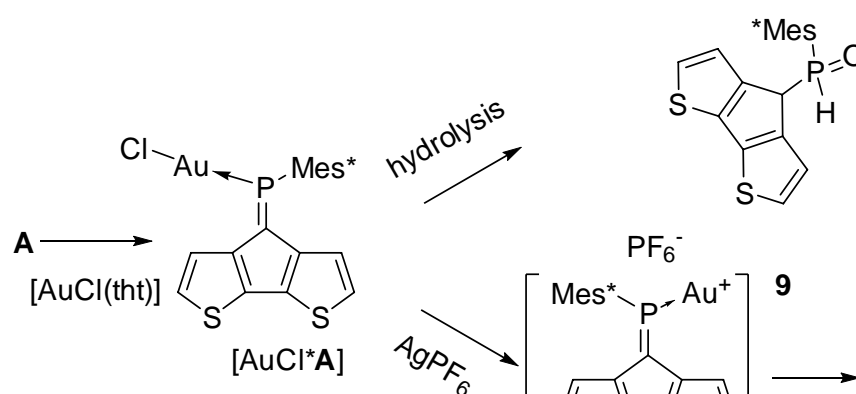<smiles></smiles><smiles>N#[W][Mg]</smiles>

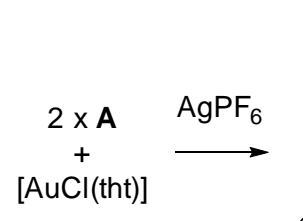

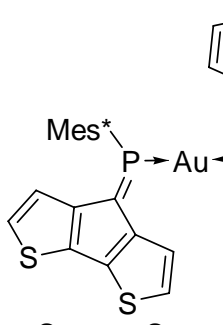<smiles></smiles><smiles>CCCCC[PbH3]</smiles><smiles>c1cc2c3c(c4ccsc4c-3s1)C2</smiles>

10

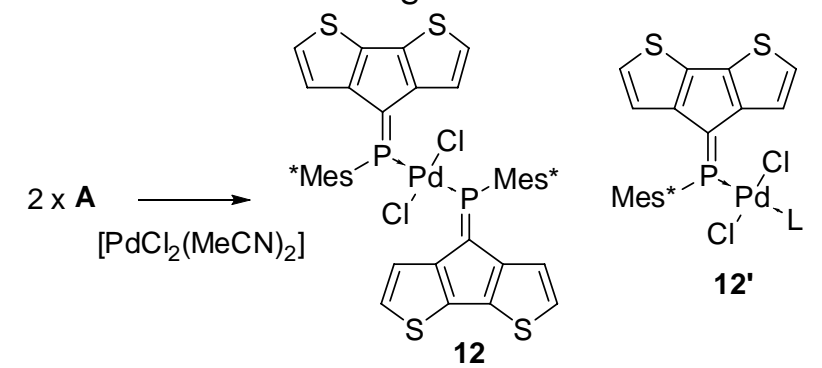<smiles></smiles>

$12 "$

Scheme 2. Metal coordination of the CDPT-phosphaalkene. The previously reported complex [AuCl*A] slowly decomposed hydrolytically with partial metal loss giving the hydrogen bonded monometallic complex $\mathbf{8}$. Formation of unstable cationic complex 9 by adding slight excess of $\mathrm{AgPF}_{6}$ to a DCM solution of $\mathbf{A}$. M ore stable derivatives are obtained by adding 2,6-dimethylphenyl isocyanide giving 10, or using two equivalents of $\mathbf{A}$ giving homoleptic complex 11. Coordination to palladium proceeds less cleanly giving the mononuclear complex $\mathbf{1 2}$ as crystallographically identified product. Reactions in THF and different stoichiometries let us assume that alternative products such as 12' or 12'" could be present in solution ( $\mathrm{s}=$ solvent).
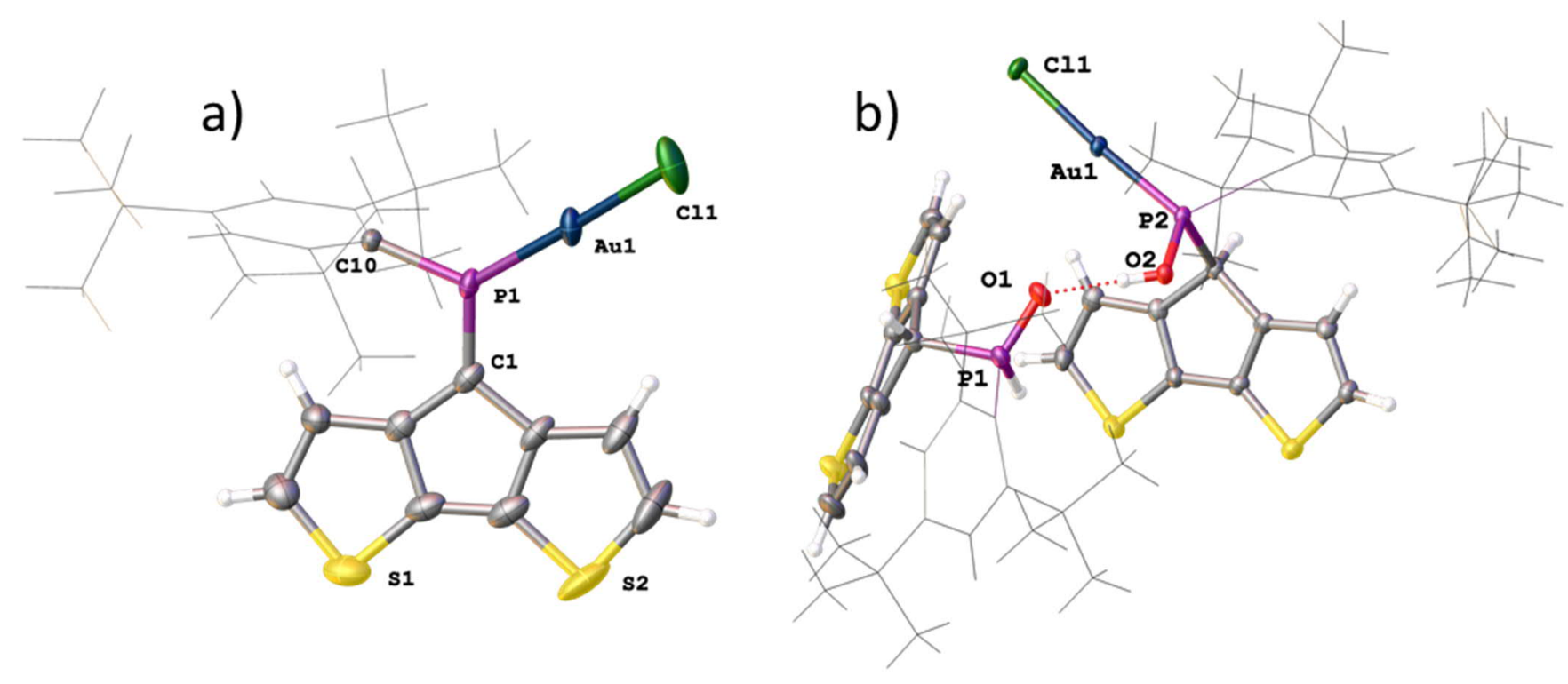
Figure 4. Solid-state-structures of $[\mathrm{AuCl} * \mathbf{A}](\mathrm{a})$ and product of its partial hydrolysis $(\mathbf{8}, \mathrm{b})$ forming the metal coordinated hydroxyphosphine hydrogen bonded to the demetallated phosphine oxide subunit. Selected bond lengths $[\AA]$ and angles [ $\left.{ }^{\circ}\right]$. [AuCl*A]: P1-C1 1.668(7), P1-C10 1.800(6), P1-Au1 2.2130(15), C1-P1-C1 108.3(3), P1Au1-Cl1 178.16(8). 8: P1-01 1.489(3), P2-02 1.578(3), P2-Au1 2.232(1), Au1-Cl1 2.298(1). 01H-02 164, $01 \cdots 02$ 2.550(4).

Complex [AuCl*A] can also be converted into a cationic gold(I) species 9 upon reaction with $\mathrm{AgPF}_{6}$ characterized by a broad shielded ${ }^{31}$ P-NM R resonance at ca. $172 \mathrm{ppm}$. However, the low coordinate gold(I) species decomposes. Over night, trace amounts of water and/ or decomposition of the $\mathrm{PF}_{6}{ }^{-}$counter ion give a cationic phosphenium species (based on the low field resonances around 320 ppm in the ${ }^{31} \mathrm{P}-\mathrm{NM}$ R spectra), which is followed by further decomposition to untraceable products and formation of a clearly visible gold mirror. Noteworthy, during this process the counter ion decomposes to trifluoro phosphane oxide (see also supporting information). The cationic intermediate can be stabilized using 2,6-dimethylphenyl isocyanide ${ }^{21}$ yielding the heteroleptic complex 10, which is characterized by a very broad ${ }^{31} \mathrm{P}-\mathrm{NM} \mathrm{R}$ resonance at $203.8 \mathrm{ppm}$ (FWHM $=316 \mathrm{~Hz}$ ) and a sharp septet of the counter ion at $-143.9 \mathrm{ppm}$. Similarly, the reaction of two equivalents of $\mathbf{A}$ with $[\mathrm{AuCl}(\mathrm{tht})]$ in the presence of silver hexafluorophosphate gives a moderately stable homoleptic complex $\mathbf{1 1}$ with a broad ${ }^{31} \mathrm{P}-\mathrm{NM} \mathrm{R}$ resonance at 197.9 ppm (FWHM ca. $125 \mathrm{~Hz}$ ). The ${ }^{31}$ P-NM R resonances of the cationic gold complexes $\mathbf{1 0}$ and $\mathbf{1 1}$ are shifted to higher frequencies compared to the gold $(I)$ chloride complex $[\mathrm{AuCl} * \mathbf{A}]\left(\delta^{31} \mathrm{P}=175.6 \mathrm{ppm}\right)$ indicating reduced electron density. Interestingly, the deshielded $\beta$ proton changes from $8.05 \mathrm{ppm}$ in [AuCl*A] to 7.58 and $7.67 \mathrm{ppm}$ in 10 and 11, respectively, illustrating the different electrostatic situations proximal to the $\mathrm{Au}(\mathrm{I})^{+}$center, whereas the shielded $\beta^{\prime}$ proton is barely influenced. The low-energy absorption band in the UV/vis spectrum of the gold complexes is red-shifted by ca. $30 \mathrm{~nm}$ upon formation of $\mathbf{9}$. This band is detected as a broad feature after coordination of the isocyanide (10) and barely visible in the homoleptic complex $\mathbf{1 1 .}$

Addition of 0.5 equivalents of $\left[\mathrm{PdCl}_{2}(\mathrm{MeCN})_{2}\right]$ to a dichloromethane solution of $\mathbf{A}$ immediately results in the formation of a dark green-brown solution. The ${ }^{31} \mathrm{P}$ NM R spectrum of the reaction mixture contains a major peak at 194 ppm which can be ascribed to $\left[\mathrm{PdCl}_{2}(\mathbf{A})_{2}\right]$ (12). Additionally, a broad peak can be observed at $162 \mathrm{ppm}$ as well as unreacted $\mathbf{A}$. we attribute these observations to the dynamic dissociation of $\mathbf{1 2}$ in solution to a monosubstituted palladium complex $\left[\mathrm{PdCl}_{2}(\mathbf{A}) \mathrm{L}\right](\mathbf{1 2}$; $\mathrm{L}=$ solvent) and free $\mathbf{A}$. The species corresponding to the peak at $162 \mathrm{ppm}$ becomes the major product when excessive amounts of $\left[\mathrm{PdCl}_{2}(\mathrm{M} \mathrm{eCN})_{2}\right]$ are used, supporting the idea that the $\mathbf{A}: \mathrm{Pd}$ ratio is closer to 1:1 in this species. Formation multi-/ di-nuclear complexes with bridging chloride ligands as in 12" is also possible (supporting information). The homoleptic complex $\mathbf{1 2}$ crystallizes as dark green needles from dichloromethane in the centrosymmetric space group P-1 with half a molecule in the asymmetric unit. The observed $\mathrm{Pd}-\mathrm{Cl}$ and Pd-P distances are 2.2902(8) and 2.3088(8) $\AA$, respectively which form a regular square planar palladium environment $\left(\mathrm{P}-\mathrm{Pd}-\mathrm{Cl} 91.64(3)^{\circ}\right)$. The resulting trans-complex shows an anti-arrangement of the ligand $\mathbf{A}$ minimizing the steric interaction of the bulky $\mathrm{M}$ es* substituents. Quite interestingly, the $\mathrm{P}=\mathrm{C}$ bond is only slightly elongated to 1.674(3) $\AA$ upon metal coordination, while the $C-P=C$ angle is significantly wider $\left(106.8(2)^{\circ}\right)$, quite similar to that of the gold complex [AuCl*A]. 
a)

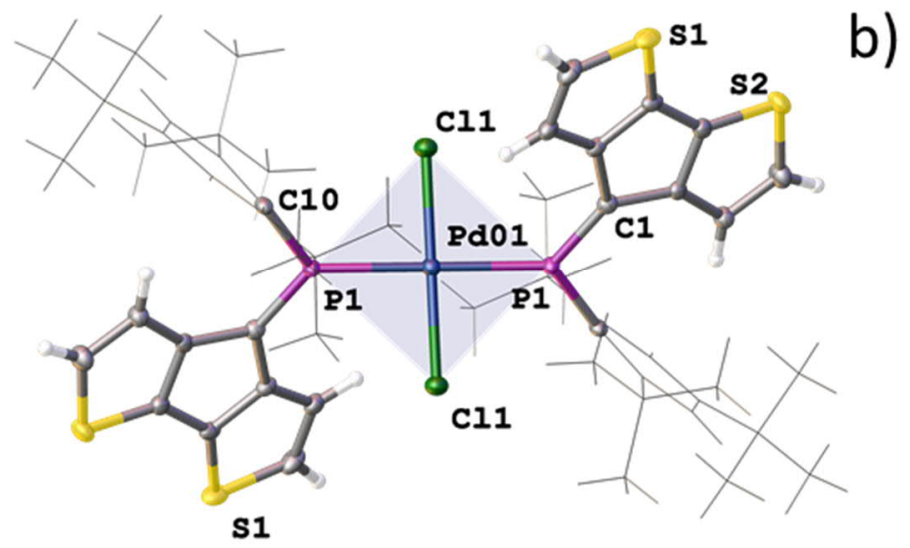

b)

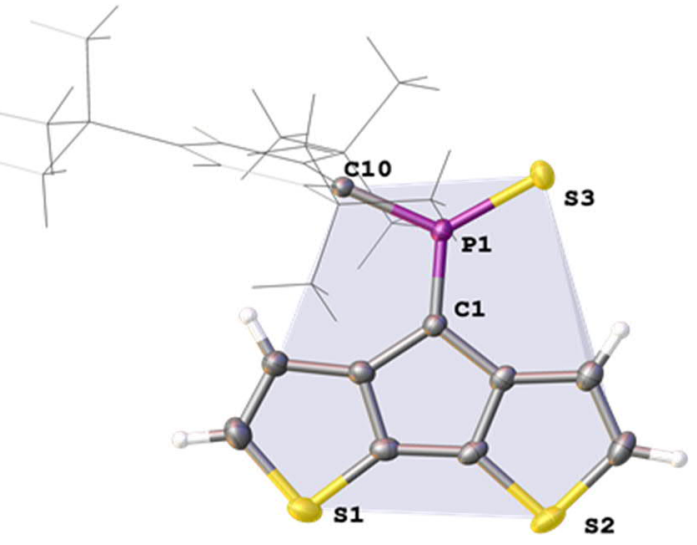

Figure 5. ORTEP plot (50\% probability ellipsoids) of the solid-state structure of palladium complex $\mathbf{1 2}$ and thiaphosphorane (13). 12: Light blue: least squares plane of the square planar Pd-coordination environment including (Pd1,P1, Cl1). Selected bond lengths $[\AA]$ and angles [ ${ }^{\circ}$ ]: $\mathrm{Cl} 1-\mathrm{Pd} 01$ 2.2902(8), P1-Pd01 2.3088(8) P1-Pd01Cl01 91.64(3). P1-C1 1.674(3), C1-P1-C(M es*) 106.8(2). 13: Light blue: least squares plane of the CPDT-PCS subunit. Selected bond lengths $[\AA]$ and angles [ $\left.{ }^{\circ}\right]$ : P1-C1 1.669(4), P1-S3 1.917(1), C1-P1-C10 111.0(2), C1-P1-S3 124.2(1).

A significantly less explored route to functionalize the phosphaalkene bonds is its oxidation with elemental chalcogens (e.g. $\mathrm{O}_{3}, \mathrm{~S}_{8}, \mathrm{Se}_{\text {grey }}$ ), the reactivity of which decreases down the group. ${ }^{22}$ While methyleneoxophosphoranes are reported to be very unstable, methylenethia- and seleno-phosphoranes have been spectroscopically characterized. ${ }^{12 b}$ The oxidation products of $M$ es $* P=C(T M S)_{2}$ are all isolable and partially stable in air. ${ }^{22 a}$ The reaction of $\mathbf{A}$ with excess of $S_{8}$ in benzene or chloroform did not afford the anticipated methylene thiaphosphorane even after refluxing for 12 hours. Similarly, A does not react with gray selenium in refluxing chloroform or dichloromethane. Interestingly, some reports describe the reaction in neat triethylamine or use small amounts of a non-nucleophilic base to promote the desired oxidation. Addition of diazabicycloundecene (DBU, 2\% in the respective solvent), results in immediate consumption of the starting material in cases of sulfur, and initiated the reaction of gray selenium. The latter gives a new species (15), with a ${ }^{31} \mathrm{P}-\mathrm{NM} R$ resonance of $144.2 \mathrm{ppm}$ and the typical ${ }^{77} \mathrm{Se}$ satellites. The coupling constant of $915.7 \mathrm{~Hz}$ is indicative of a very high s-character of the P-Se bond compared to e.g. phosphine selenides, which typically have coupling constants of around $750 \mathrm{~Hz}$. Previous work by Appel and co-workers already hinted at this situation with a large ${ }^{1}$ pse of $890 \mathrm{~Hz}$. Some examples of selenoiminophosphirenes are currently still the representatives with the largest P-Se coupling constants $(960 \mathrm{~Hz})$. $^{22 a}$

In case of the sulfur reaction, the crude reaction mixture presents three new resonances in the ${ }^{31} \mathrm{P}-\mathrm{NM} \mathrm{R}$ spectra at around 160,80 , and $0 \mathrm{ppm}$. The latter signal is tentatively assigned to the di-oxidized species 14 based on 2D-NM R data (see supporting information) and literature references. ${ }^{23}$ Chromatographic workup of the crude mixture on silica gel (DCM/pentane) allowed isolation of the thiaphosphorane (13) with a characteristic ${ }^{31} \mathrm{P}-\mathrm{NM} \mathrm{R}$ resonance at 157.2 ppm. The more deshielded ${ }^{31}$ P-NMR signal for $\mathbf{1 3}$ compared to $\mathbf{1 5}$ agrees with the slightly higher electronegativity of sulfur favoring the ionic resonance structure (I). The $\beta^{\prime}$ protons are again strongly shielded (13: 4.48 and 7: $4.53 \mathrm{ppm}$ ) suggesting similar orientation of the $M$ es* group. The close proximity to the chalcogen atoms has also a strong impact on the $\beta$-proton resonances shifting them to higher frequencies (13: 7.88 and 15: $8.09 \mathrm{ppm})$.

Yoshifuji and co-workers have described the thermal conversion of the methylenethiaphosphorane into the thiaphosphirane, however we were unable to trigger this conversion to give $\mathbf{1 3}^{\prime}{ }^{23}$

The formation of $\mathbf{1 3}$ was structurally confirmed by SC-XRD; $\mathbf{1 3}$ crystallizes in the hexagonal space group P6 ${ }_{5}$ as dark red blocks. The CPDT core displays the expected co-planarity with the exocyclic unsaturated CPS fragment. The PC $(1.669(4) \AA)$ and PS (1.917(1) $\AA$ ) bonds are in the typical range of strong double bonds. The angle of the $\mathrm{P}=\mathrm{C}$ unit towards the Mes* and S are 111.0(2) and 124.2(1); the former being much wider compared to the parent 
compound as well as the metallated derivatives 12 and [AuCl*A]. The thiaphosphorane unit is coplanar with the CPDT core efficiently extending the $\pi$-conjugated framework. The NBO analysis carried out on these thia- and selenophosphoranes support the strong contribution of the ionic resonance forms in Scheme 3(a) having strong $\mathrm{P}\left(\delta^{+}\right) \mathrm{Ch}\left(\delta^{-}\right)$character and no $\mathrm{d}$-orbital contributions from phosphorus in agreement also with the common views of hypervalency in p-block compounds. The significantly larger polarization in the thiaphosphorane compared to the selenophosphorane is evidenced by the relatively higher negative NBO charge at sulfur (-0.52) compared to Se (0.45). (vide infra and supporting information).

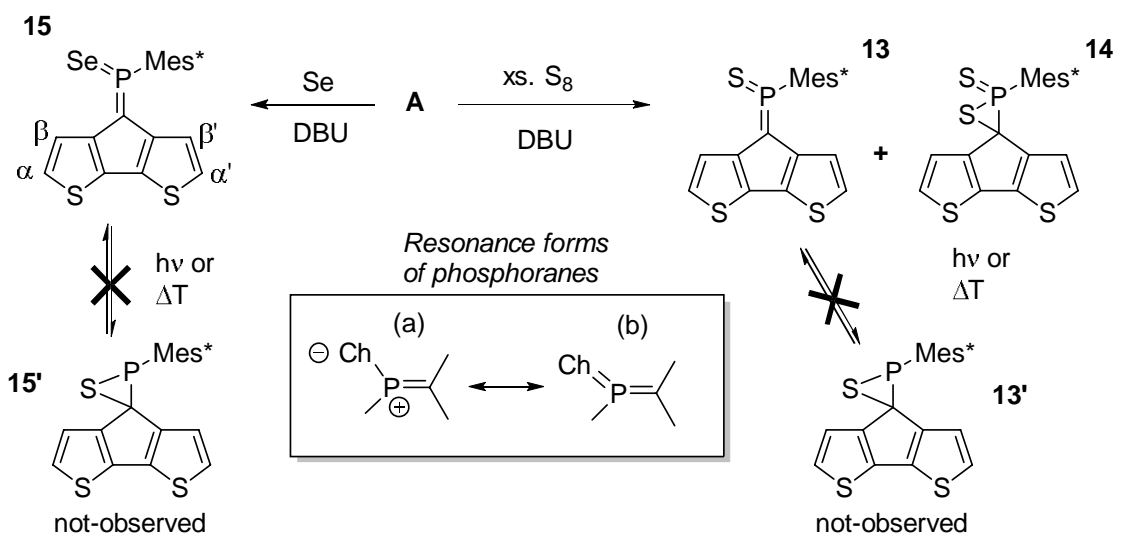

Scheme 3. Top: Functionalization of the CPDT phosphaalkene using $\mathrm{S}_{8}$ and $\mathrm{Se}_{\text {grey }}$ as oxidants. Thiaphosphorane (13) and Selenophosphorane (15) could be isolated using column chromatography as ambiently stable compounds. Rearrangement of the thiaphosphorane into the thiaphosphirane was not observed under various conditions. ${ }^{\text {a }}$ Bottom: Relevant resonance structures of the phosphoranes. ${ }^{a}$ The compound with a ${ }^{31}$ P-NM R resonance of -1.26 ppm was isolated by column chromatographic work-up. 2D NMR analysis indicates a P-C(CPDT) single bond, and the ${ }^{31}$ P-NM R resonance agrees with the formation of 14.

In order to elucidate the impact of the modifications of the parent CPDT phosphaalkene $\mathbf{A}$ we performed a detailed theoretical study including the newly synthesized and further in silico derivatives. For all calculated systems the Mes* substitutent has been replaced by the electronically similar, but computational simpler mesityl (Mes) substituent. We have focused on the electronic impact of the derivatizations in the ground state and its consequences for the excited states. The structures are optimized in their ground state using a continuum solvation model for DCM at the DFT cam-B3LYP/6-311G** level of theory. At least 30 singlet and triplet transitions are calculated using time-dependent DFT (TD-DFT). As previously noted ${ }^{14}$ the charge transfer character complicates computation of the transition energies, thus we scaled the low-energy transitions to the experimentally observed absorption maximum of $\mathbf{A}$ with respect to the calculated value of (I). 

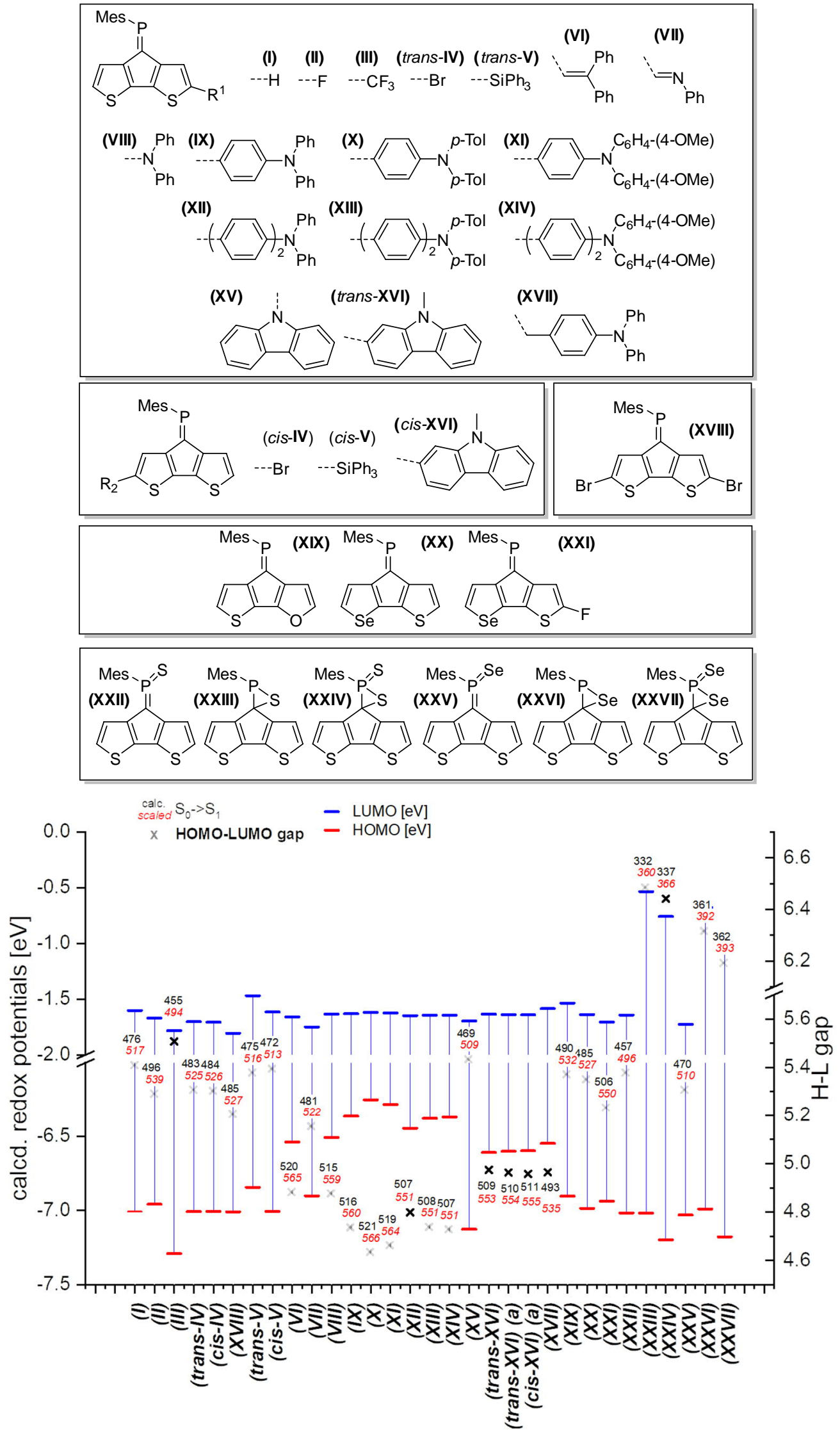

Figure 5. Top: depiction of all theoretically studied systems using the simplified mesityl (1,3,5-trimethylphenyl) phosphorus protecting group at the TD-DFT cam-B3LYP/6-311G** level of theory using the continuum solvation model for DCM. Bottom: Summarized results of the optical and electronic data of the studied systems. The 
calculated lowest energy absorption energy/wavelength (grey number) is scaled with respect to the experimental wavelength for $\mathbf{A}$ (red numbers). The theoretical Eg (cross) is depicted on the secondary axis (right). HOM O and LUMO energy levels are provided in eV.

Substitution of the core with electron withdrawing halogen substituents (II, III, trans-/ cis-IV, and XVIII) has a notable stabilizing influence on the LUM $O$ energies compared to the parent model compound (I). No significant effects on the HOM O levels have been noted, with the exception of fluoride which also results in the low est energy absorption. Introducing a silyl group (cis- and trans-V) leads to a destabilization of both HOMO and LUM O levels, however with no net effect on the absorption energies (or $E_{g}=$ HOM O-LUMO gap). The dibromoderivative 2 shows a slightly milder reduction potential compared to the parent compound which is in line with the calculated LUM 0 levels of I and XVIII. Noteworthy, the introduction of these substituents has almost no influence on the extinction coefficients of the low energy transitions. Both, alkene (VI) and imine (VII) derivatives lead to an increased transition probability (by a factor of three to five), however only the imine (VII) substituent also causes a pronounced red-shift. Similar effects are obtained using diphenyl (VIII), and triphenylamine (IX - XI) substitutions. The electron richer ditolyl(phenyl)amine derivative $(\mathbf{X})$ is most red-shifted in this series. Separating the donor and acceptor moieties by another phenyl linker has no further effects on the orbital shapes and transition energies.

Interestingly, the $\mathrm{N}$-linked carbazole derivative (XV) displays a blue shifted low-probability absorption (0.04), while the 2-linked N-methyl carbazole (XVI) shows red-shifted absorption and increased transition probabilities $(0.08)$. This is explained by the different donor sites within the seemingly similar derivatives. The former has a CPDT localized HOM O, while the latter has a significantly extended HOMO stretching over the carbazole and the CPDT core leading to a pronounced charge-transfer character. In order to further support these findings, electrochemical analyses of isomeric $\mathbf{7}$ were carried out. The CPDT-phosphaalkene core gives rise to a reversible reduction at $\mathrm{E}_{1 / 2}$ $1.806 \mathrm{~V}\left(\mathrm{vs}\right.$. $\left.\mathrm{Fc} / \mathrm{Fc}^{+}\right)$, which is shifted to more negative potentials compared to the parent compound $\mathbf{A}\left(\mathrm{E}_{1 / 2}-1.62 \mathrm{~V}\right)$. In contrast to $\mathbf{A}$, we observe a reversible oxidation at $0.277 \mathrm{~V}$ and a quasi-reversible oxidation $0.650 \mathrm{~V}$, followed by an irreversible oxidation around $1.08 \mathrm{~V}$. The former two are assigned to the (quasi-)reversible oxidation of the carbazole moiety, while the latter is attributed to the irreversible oxidation of the CPDT-phosphaalkene core similar to that observed in $\mathrm{A}(+0.84 \mathrm{~V})$. These experimental values are corroborated by the $0.4 \mathrm{eV}$ lower LUM 0 levels of $\mathbf{X V I}$ compared to parent phosphaalkene $\mathbf{I}$. The different isomers have almost identical optical properties, and their free energies are within less than $0.5 \mathrm{kcal} \mathrm{mol}^{-1}$ substantiating that different isomers can be present in solution.
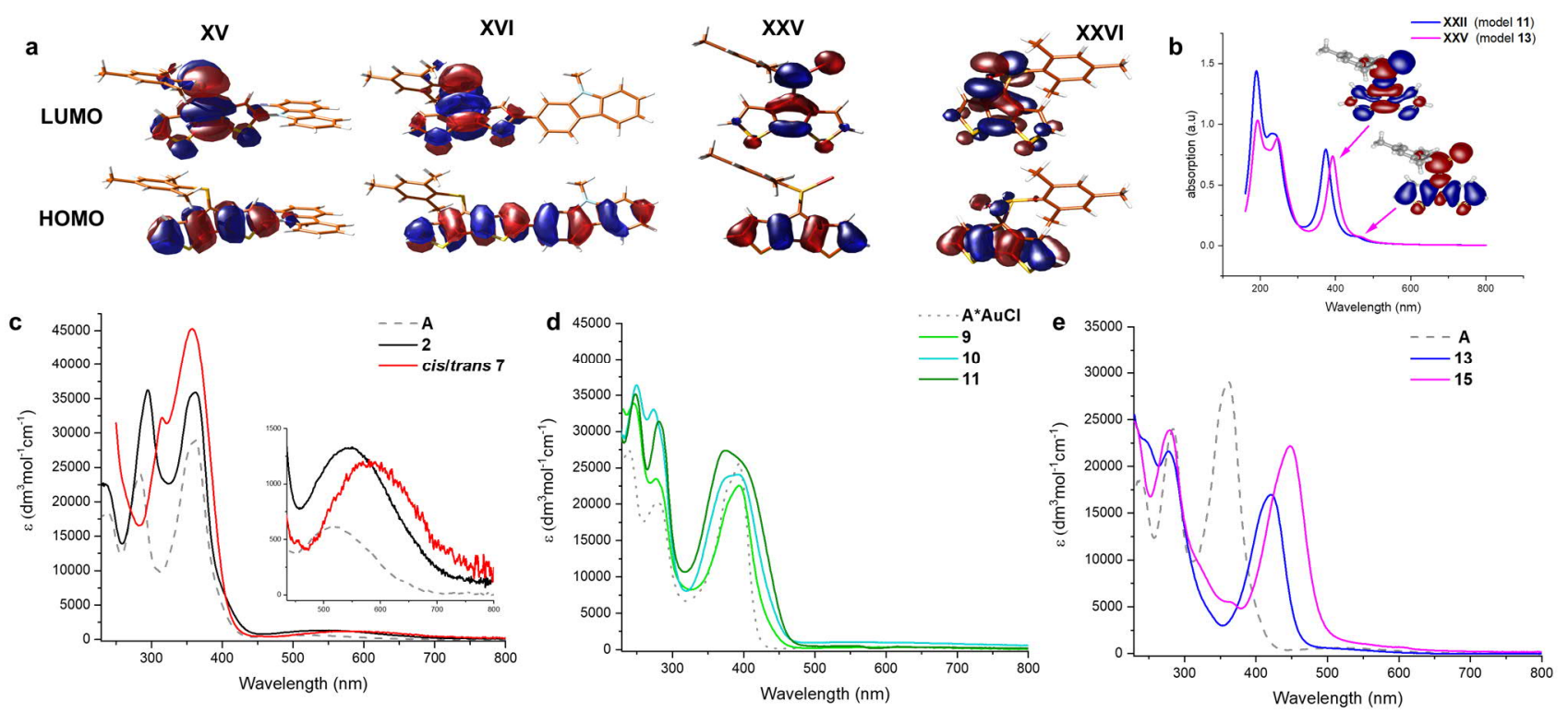

Figure 6. a) Calculated Frontier molecular orbitals of selected derivatives. b) calculated spectra of XXII and XXV (models of derivatives $\mathbf{1 3}$ and 15), including the EDDM s of the two lowest energy transitions of $\mathbf{X X V} . \mathbf{C}, d \&$ e) optical 
spectra of compounds $\mathbf{2}, \mathbf{7}, \mathbf{9},{ }^{a} \mathbf{1 0},{ }^{a} \mathbf{1 1}, \mathbf{1 3}, \mathbf{1 5}$, and the literature reported $\mathbf{A},\left[\mathbf{A}^{*} \mathrm{AuCl}\right]$. Solvent: $\mathrm{DCM}$. ${ }^{\mathrm{a}}$ due to the facile decomposition of these cationic complexes the extinction coefficients are only approximated.

Quite surprising is the small impact of replacing the thiophene for selenophene or furan rings, i.e. modifying the core of the donor unit, only slightly shifting the absorption energies and not affecting the transition probabilities. A moderate impact could be achieved combining core modification with fluorine- substitution at the $\alpha$-position (XIX vs. $\mathbf{X X I ) .}$

We also studied the chemical functionalization at the P-center (and the double bond) using sulfur and selenium oxidations.

The thiaphosphorane (XXIII) is less stable $\left(\Delta G=+1.4 \mathrm{kcal} \mathrm{mol}^{-1}\right)$, than the methylenethiaphosphorane (XXII); similarly, the selephosphirane $(\mathbf{X X V})$ is less table $\left(\Delta G=+2.9 \mathrm{kcal} \mathrm{mol}^{-1}\right)$ than the isomeric methyleneselenophosphorane (XXVI). The frontier molecular orbitals of the methylenephoshoranes are quite similar to those of unsubstituted $\mathbf{A}$ (and e.g. $\mathrm{Au}^{+}$coordinated derivative) with CPDT localized bonding $\pi$ orbitals and fulvenoid based anti-bonding orbitals that involve the PS (or Se) moiety. The electronic properties of these two systems (13 and 15) have also been probed by means of electrochemical analysis showing clear differences but also a number of similarities. The oxidative side shows two irreversible processes at slightly milder potentials for the sulfur-derivative 13 compared to the selenophopshorane. (13: 0.671 and $0.905 \mathrm{~V} ; 15: 0.707$ and $1.012 \mathrm{~V}$ ). The reductive side is however markedly different. In the case of $\mathbf{1 3}$ a mild irreversible reduction $\left(\mathrm{E}_{1 / 2}-1.585 \mathrm{~V}\right)$ is followed by a reversible reduction $(-1.944 \mathrm{~V})$. In contrast, 15 shows an irreversible reduction at $-1.658 \mathrm{~V}$, followed by a chemical step (reoxidation at $-0.640 \mathrm{~V}$ ). This initial $\mathrm{EC}$ process is followed by a quasi-reversible reduction at $\mathrm{E}_{1 / 2}=-$ $1.956 \mathrm{~V})$. The small difference in the oxidative process is in line with the HOMO, being mainly localized on the "organic core", while the different reductive behavior agrees with the localization of the LUMO on the heterofulvenoid +chalcogen framework. Model compounds of the radical anions (for S:XXII'- and Se: XXV') have been investigated showing only small differences in spin and charge localization. The chalcogen atoms negative charge is slightly higher on Se $(-0.73$ for Se and -0.71 for $\mathrm{S})$, however the significantly larger radius implies less nucleophilic character. On the other hand, the spin density at the $\mathrm{P}$ atom is higher for $\mathbf{X X I I}^{-}(0.30)$ compared to XXV (0.27). In the latter case, spin density is increased at the chalcogen and phosphaalkene carbon (XXV: ${ }^{\prime}$ Se 0.14 and $\underline{C}=P 0.31$ vs. XXII- $S: 0.13$ and $\underline{C}=P: 0.28$ ), which might indicate a more facile rearrangement to the threemembered ring structure of the Se-derivative compared to its lighter S-analogue.

The FM Os of the phopshirane have significant bonding and antibonding contributions from the three-membered ring as well as the CPDT core. The calculated $S_{0} \rightarrow S_{1}$ transitions are slightly blue-shifted for the phosphoranes (XXII: 457 (496) nm and XXV: 470 (510) nm) compared to the parent motif (I: 476 (517) nm), and dramatically blue shifted for the corresponding phosphiranes (XXIII: 332(360) nm and XXVI: 361 (392) nm). These calculations also support the observed inability to trigger conversion of phosphoranes $\mathbf{1 3}$ and $\mathbf{1 5}$ in the isomeric phosphiranes $\mathbf{1 3}$ ' and $\mathbf{1 5}$ ' by illumination or at elevated temperatures. 
a)

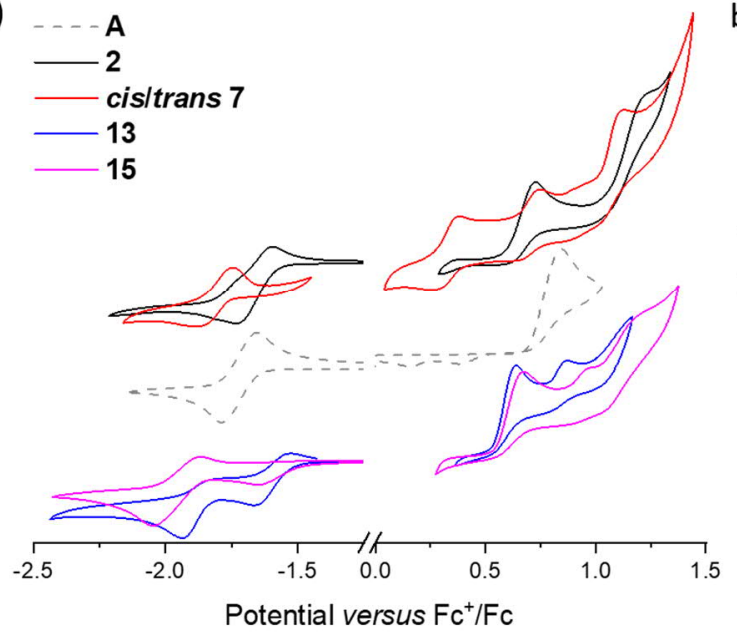

b)

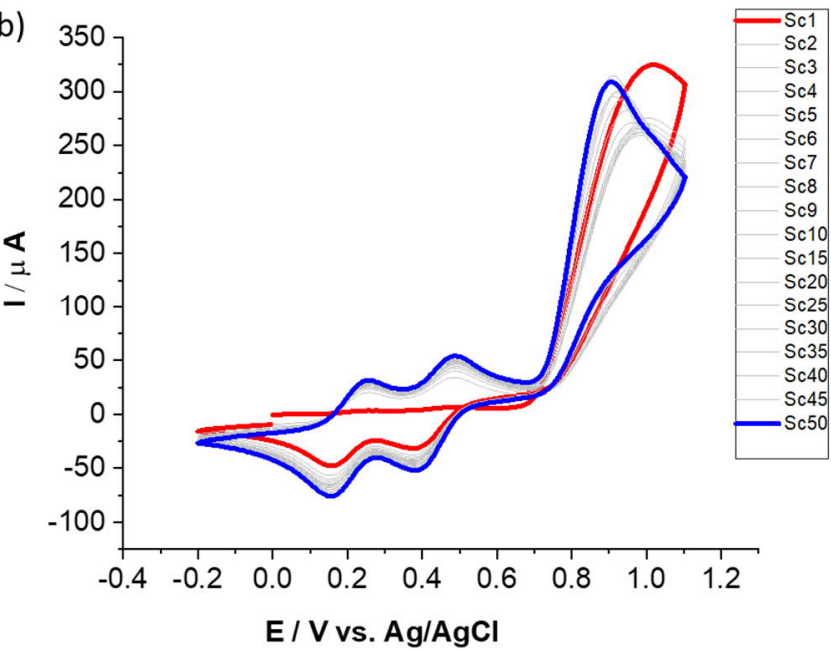

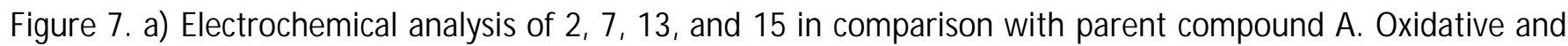
reductive scans at a scan rate of $100 \mathrm{mV} \mathrm{s}^{-1}$. Three electrode setup with a glassy carbon working electrode (WE), Ag wire reference electrode; $\mathrm{DCM} / \mathrm{Bu}_{4} \mathrm{NPF}_{6}(0.1 \mathrm{M})$ solution; referenced to the $\mathrm{Fc}^{+} / \mathrm{Fc}$ couple. The voltammograms are offset and scaled. b) Electropolymerisation of $\mathbf{A}(1 \mathrm{mM})$ by repetitive oxidative cycling $(-0.2 \mathrm{~V}$ to $+1.1 \mathrm{~V})$ at a scan rate of $100 \mathrm{mV} \mathrm{s}^{-1}$. First (red trace) and $50^{\text {th }}$ (blue trace) are highlighted indicating the increased current due to material deposition at the WE.

Re-investigation of the parent phosphaalkenes (A) electro-chemistry revealed that oxidative cycling gives rise to two new reversible redox features. These are accompanied with a gradual shift of the main oxidation peak to milder potential. Based on our previous work we assign this behavior to an oxidative electro-polymerization based on the CPDT core (Fig. 7). Detailed investigations of the films for organic electronics applications are currently under way.

\section{Conclusions}

In this manuscript, we have experimentally and theoretically illustrated that the cyclopentadithiophenephosphaalkene core $(\mathbf{A})$ is an interesting building block for optically and electronically tunable materials. This core offers a large variety of possible functionalization including the organic core as well as the exocyclic phosphaalkene unit. Oxidation of the P-centre with chalcogens and introduction of a donor substituent at the $\alpha$, $\alpha^{\prime}$-position are most promising. Theoretical studies support these findings and provide further examples of suitable functionalizations. Our current efforts are directed towards using these systems in opto-electronic devices.

\section{Acknowledgements}

The authors would like to thank the Swedish research council (Vetenskapsrådet), the Carl-Trygger foundation, LarsHiertas minne, and the Olle-Engkvist foundation for their continuous support.

\section{Notes and references}

¥ The supporting information contains the complete experimental and spectroscopic data for this manuscript. CCDC 2003575 - 2003582 entries contain additional crystallographic information. These data can be obtained free of charge via www.ccdc.cam.ac.uk/data_request/cif, or by emailing data_request@ccdc.cam.ac.uk. Experimental details synthetic procedures, spectroscopic and theoretical data can be found in the supporting information. 
1. A. Arjona-Esteban, M. R. Lenze, K. Meerholz and F. Würthner, in Elementary Processes in Organic Photovoltaics, ed. K. Leo, Springer International Publishing, Cham, 2017, DOI: 10.1007/978-3-319-283388_8, pp. 193-214.

2. P. Coppo and M. L. Turner, J. Mater. Chem., 2005, 15, 1123-1133.

3. M. Horie, L. A. M ajewski, M. J. Fearn, C.-Y. Yu, Y. Luo, A. Song, B. R. Saunders and M. L. Turner, J. M ater. Chem., 2010, 20, 4347-4355.

4. a) J. S. Reddy, T. Kale, G. Balaji, A. Chandrasekaran and S. Thayumanavan, J. Phys. Chem. Let., 2011, 2, 648654; b) S. Wanwong, A. Poe, G. Balaji and S. Thayumanavan, Org. Biomol. Chem., 2014, 12, 2474-2478.

5. J. D. Azoulay, Z. A. Koretz, B. M. Wong and G. C. Bazan, M acromolecules, 2013, 46, 1337-1342.

6. a) R. Hoffmann, Angew. Chem. Int. Ed., 1982, 21, 711-724; b) R. Appel, F. Knoll and I. Ruppert, Angew. Chem. Int. Ed., 1981, 20, 731-744; c) R. Pietschnig and A. Orthaber, in Reference Module in Chemistry, Molecular Sciences and Chemical Engineering, Elsevier, 2016, DOI: 10.1016/b978-0-12-409547-2.117214.

7. a) M. A. Shameem and A. Orthaber, Chem. Eur. J., 2016, 22, 10718-10735; b) F. Vidal and F. Jakle, Angew. Chem. Int. Ed., 2019, 58, 5846-5870.

8. J. P. Green and A. Orthaber, in Encyclopedia of Inorganic and Bioinorganic Chemistry, ed. R. A. Scott, 2019, DOI: 10.1002/9781119951438.eibc2716, pp. 1-46.

9. a) L. Chen, B. W. Rawe, K. Adachi and D. P. Gates, Chem. Eur. J., 2018, 24, 18012-18019; b) K. Dück, B. W. Rawe, M. R. Scott and D. P. Gates, Angew. Chem. Int. Ed., 2017, 56, 9507-9511; c) V. A. Wright and D. P. Gates, Angew. Chem. Int. Ed., 2002, 41, 2389-2392; d) R. C. Smith and J. D. Protasiewicz, J. Am. Chem. Soc., 2004, 126, 2268-2269; e) D. M orales Salazar, E. Mijangos, S. Pullen, M. Gao and A. Orthaber, Chem. Commun., 2017, 53, 1120-1123.

10. a) S. Ikeda, F. Ohhata, M. M iyoshi, R. Tanaka, T. M inami, F. Ozawa and M. Yoshifuji, Angew. Chem. Int. Ed., 2000, 39, 4512-4513; b) M. Freytag, S. Ito and M. Yoshifuji, Chem. Asian J., 2006, 1, 693-700; c) J. DugalTessier, G. R. Dake and D. P. Gates, Organometallics, 2007, 26, 6481-6486.

11. a) S. Ito, M. Freytag and M. Yoshifuji, Dalton Trans., 2006, 710-713; b) E. Öberg, A. Orthaber, C. Lescop, R. Réau, M. Hissler and S. Ott, Chem. Eur. J., 2014, 20, 8421-8432.

12. a) P. M. Petrar, G. Nemes, I. Silaghi-Dumitrescu, H. Ranaivonjatovo, H. Gornitzka and J. Escudié, Chem. Commun., 2007, 40, 4149-4151; b) T. A. van der Knaap, M. Vos and F. Bickelhaupt, J. Organomet. Chem., 1983, 244, 363-367; c) H. M iyake, T. Sasamori and N. Tokitoh, Phosphorus, Sulfur Silicon Relat. Elem., 2015, $190,1247-1250$.

13. P. K. Majhi, K. C. F. Chow, T. H. H. Hsieh, E. G. Bowes, G. Schnakenburg, P. Kennepohl, R. Streubel and D. P. Gates, Chem. Commun., 2016, 52, 998-1001.

14. A. El Nahhas, M. A. Shameem, P. Chabera, J. Uhlig and A. Orthaber, Chem. Eur. J., 2017, 23, 5673-5677.

15. V. B. Gudimetla, A. L. Rheingold, J. L. Payton, H.-L. Peng, M. C. Simpson and J. D. Protasiewicz, Inorg. Chem., 2006, 45, 4895-4901.

16. H.-L. Peng, J. L. Payton, J. D. Protasiewicz and M. C. Simpson, J. Phys. Chem. A, 2009, 113, 7054-7063.

17. O. V. Dolomanov, L. J. Bourhis, R. J. Gildea, J. A. K. Howard and H. Puschmann, J. Appl. Crystallogr., 2009, 42, 339-341. 
18. a) A. Orthaber, J. H. Albering, F. Belaj and R. Pietschnig, J. Fluorine Chem., 2010, 131, 1025-1031; b) A. S. Ionkin, W. J. Marshall, B. M. Fish, M. F. Schiffhauer and C. N. M EEwen, Chem. Commun., 2008, DOI: 10.1039/B809877H, 5432-5434.

19. a) S. B. Clendenning, P. B. Hitchcock and J. F. Nixon, Chem. Commun., 1999, DOI: 10.1039/A903745D, 1377-1378; b) A. G. Ginzburg, V. V. Bashilov, F. M. Dolgushin, A. F. Smol'yakov, P. V. Petrovskii and V. I. Sokolov, Inorg. Chim. Acta, 2011, 370, 292-296; c) M. Doux, N. Mézailles, L. Ricard and P. Le Floch, Eur. J. Inorg. Chem., 2003, 2003, 3878-3894; d) J. Francos, D. Elorriaga, P. Crochet and V. Cadierno, Coord. Chem. Rev., 2019, 387, 199-234.

20. a) J. Bader, R. J. F. Berger, H.-G. Stammler, N. W. M itzel and B. Hoge, Chem. Eur. J., 2011, 17, 13420-13423; b) H. Tavakol and F. Keshavarzipour, Heteroat. Chem, 2016, 27, 210-220.

21. V. P. Dyadchenko, N. M. Belov, M. A. Dyadchenko, Y. L. Slovokhotov, A. M. Banaru and D. A. Lemenovskii, Russ. Chem. Bull., 2010, 59, 539-543.

22. a) R. Appel and C. Casser, Tetrahedron Lett., 1984, 25, 4109-4112; b) K. V. Turcheniuk, A. B. Rozhenko and I. V. Shevchenko, Eur. J. Inorg. Chem., 2011, 2011, 1762-1767; c) B. Hoge, J. Bader, H. Beckers, Y. S. Kim, R. Eujen, H. Willner and N. Ignatiev, Chem. Eur. J., 2009, 15, 3567-3576.

23. a) T. Kozo, S. Kazuho, T. Hiroaki and Y. Masaaki, Chem. Lett., 1994, 23, 1927-1930; b) T. Kozo, T. Hiroaki, S. Kazuho and Y. M asaaki, Bull. Chem. Soc. Jpn., 1996, 69, 141-145. 